This document is confidential and is proprietary to the American Chemical Society and its authors. Do not copy or disclose without written permission. If you have received this item in error, notify the sender and delete all copies.

\title{
Unravelling the improved electronic and structural properties of methyl ammonium lead iodide deposited from acetonitrile
}

\begin{tabular}{|r|l|}
\hline Journal: & Chemistry of Materials \\
\hline Manuscript ID & cm-2018-030844.R2 \\
\hline Manuscript Type: & Article \\
\hline Complete List of Authors: & $\begin{array}{l}\text { Ramadan, Alexandra; University of Oxford, Physics } \\
\text { Noel, Nakita; University of Oxford, Physics } \\
\text { Fearn, Sarah; Imperial College London Department of Materials } \\
\text { Young, Neil; University of Oxford, Department of Materials } \\
\text { Walker, Marc; University of Warwick, Department of Physics } \\
\text { Rochford, Luke; University of Warwick, Chemistry } \\
\text { Snaith, Henry; University of Oxford, Physics }\end{array}$ \\
\hline
\end{tabular}


Unravelling the improved electronic and structural properties of methyl ammonium lead iodide deposited from acetonitrile

Alexandra J. Ramadan ${ }^{1 \dagger}$, Nakita K. Noel², Sarah Fearn³ ${ }^{3}$ Neil Young ${ }^{4}$, Marc Walker ${ }^{5}$, Luke A. Rochford $^{6}$, Henry J. Snaith ${ }^{1 \dagger}$

1. Clarendon Laboratory, Department of Physics, University of Oxford, Oxford, OX1 3PU, U.K.

2. Department of Electrical Engineering, Princeton University, Princeton, NJ, 08540, U.S.

3. Department of Materials, Imperial College London, South Kensington, SW7 2BP, U.K.

4. Department of Materials, University of Oxford, Oxford, OX1 3PH, U.K.

5. Department of Physics, University of Warwick, Coventry, CV4 7AL, U.K.

6. School of Chemistry, University of Birmingham, Edgbaston, B15 2TT, U.K.

\begin{abstract}
Perovskite-based photovoltaics are an emerging solar technology with lab scale device efficiencies of over $22 \%$, and significant steps are being made towards their commercialisation. Conventionally high efficiency perovskite solar cells are formed from high boiling point, polar aprotic solvent solutions. Methylammonium lead iodide $\left(\mathrm{CH}_{3} \mathrm{NH}_{3} \mathrm{PbI}_{3}\right)$ films can be made from a range of solvents and blends, however the role the solvent system plays in determining the properties of the resulting perovskite films is poorly understood. Acetonitrile (ACN), in the presence of methylamine (MA), is a viable non-toxic solvent for fabrication of $\mathrm{CH}_{3} \mathrm{NH}_{3} \mathrm{PbI}_{3}$ photovoltaic devices with efficiencies $>18 \%$. Herein we examine films prepared from ACN/MA and dimethylformamide (DMF) and scrutinize their physical and electronic properties using spectroscopy, scanning probe imaging and ion scattering. Significant differences are
\end{abstract}


observed in the chemistry and electronic structure of $\mathrm{CH}_{3} \mathrm{NH}_{3} \mathrm{PbI}_{3}$ films made with each solvent, ACN/MA producing films with superior properties resulting in more efficient photovoltaic devices. Here we present a holistic and complete understanding of a high performance perovskite material from an electronic, physical and structural perspective and establish a robust toolkit with which to understand and optimise photovoltaic perovskites.

\section{INTRODUCTION}

Lead-halide perovskite photovoltaics have emerged in the past five years as a field with great potential to provide cheap, renewable energy. ${ }^{1}$ The efficiencies of perovskite photovoltaic devices are now approaching $23 \%$, bringing the technology in line with the performance of conventional silicon photovoltaics and making them the fastest developing solar technology to date. ${ }^{2}$ The uniquely rapid improvement in power conversion efficiencies has led to considerable interest in the transfer of this technology to commercial products. The most commonly used processing solvents include dimethylformamide (DMF), dimethylsulfoxide (DMSO) and $\gamma$ butyrolactone (GBL), DMF and GBL have significant toxicity concerns, which inhibit their employment in large scale manufacturing. To enhance these material's commercial viability, research has begun to develop solvent systems with reduced toxicity, suitable for industrial use. Noel and co-workers demonstrated that an acetonitrile/methylamine (ACN/MA) solvent system can be used to create high performance methylammonium lead iodide $\left(\mathrm{CH}_{3} \mathrm{NH}_{3} \mathrm{PbI}_{3}\right)$ solar cells. ${ }^{3}$ ACN is a low toxicity solvent which is currently employed in a wide variety of industrial processes, making it a suitable candidate for large-scale perovskite processing. ${ }^{4}$ The addition of MA to ACN allows the solvation of perovskite precursors at concentrations useful for thin film and device fabrication. Although the chemical process is not yet fully understood it has been suggested that methylamine solvates the perovskite by "melting" the precursors (through 
coordination of the MA to the perovskite) and resulting in the formation of an intermediate liquid perovskite phase. ${ }^{5,6}$ This liquid perovskite phase is miscible with acetonitrile resulting in a fully homogeneous, colloid free solution. ${ }^{3}$ It would, therefore, appear that the chemistry at work in solvent mixtures is significantly different from that reported for more commonly utilised solvents. Solvents capable of strong $\mathrm{Pb}$ ion co-ordination (such as DMSO) have been suggested to bond most strongly with lead halide precursors and influence the crystallisation of films. ${ }^{7}$ In addition to this solutions containing DMF and DMSO form colloidal perovskite suspensions the size and concentration of which are critical to film formation. ${ }^{8}$ This ultimately influences the nucleation and rate of crystallisation of perovskite solutions in to thin films. ${ }^{9,10}$

It is apparent, throughout the literature, that subtle differences in the processing conditions of perovskites can result in vastly different film properties and device performances. Solvent choice, ratios of perovskite precursors, annealing times/temperatures and the method of deposition all exert considerable influence over physical and electronic properties. ${ }^{10-15}$ If the commercialisation of perovskite photovoltaics is to be realised, a thorough understanding of how the fundamental properties of these materials can be influenced, and ultimately controlled, is paramount.

In this work the chemical, electronic, and structural properties of $\mathrm{CH}_{3} \mathrm{NH}_{3} \mathrm{PbI}_{3}$ thin films prepared from a variety of processing solvents are investigated. Particular focus is placed on the differences between films processed from DMF and ACN/MA solvents. We determine that the properties of films formed from ACN/MA are more desirable for photovoltaic applications than their DMF analogues.

RESULTS AND DISCUSSION 
To compare the structural and electronic differences between films fabricated from DMF and ACN/MA the following solvent systems and deposition methods were used: DMF (one-step processing), DMF (anti-solvent quench, DMF-SQ), ACN/MA compound solvent (one-step), and ACN/MA with the addition of a $\mathrm{CH}_{3} \mathrm{NH}_{3} \mathrm{Cl}$ post-treatment $\left(\mathrm{ACN} / \mathrm{CH}_{3} \mathrm{NH}_{3} \mathrm{Cl}\right)$. All thin films were deposited onto fluorine-doped tin oxide (FTO) coated glass through spin-coating as detailed in the experimental section. The DMF (one-step) processing route is known to result in suboptimal photovoltaic devices - introduction of a solvent quenching step during spin-coating is most commonly used to enhance high performance $\mathrm{CH}_{3} \mathrm{NH}_{3} \mathrm{PbI}_{3}$ solar cells..$^{16,17}$

Atomic force microscopy (AFM) and scanning kelvin probe microscopy (SKPM), were used to measure the differences in morphology and surface potential variation of $\mathrm{CH}_{3} \mathrm{NH}_{3} \mathrm{PbI}_{3}$ films (Figure 1).

(a)

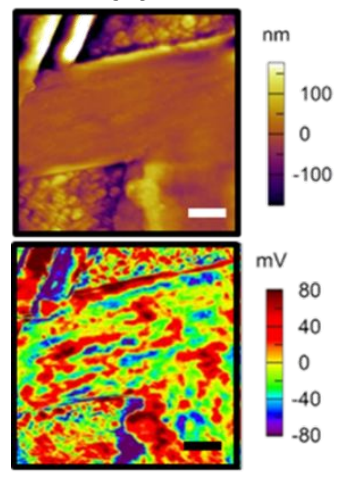

(b)

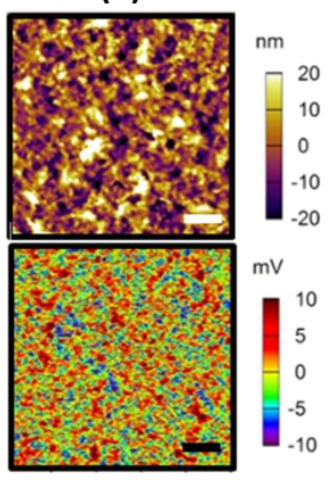

(c)

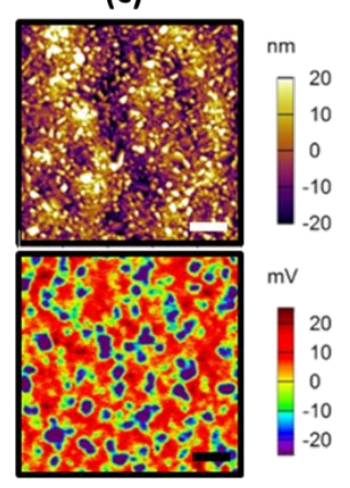

(d)

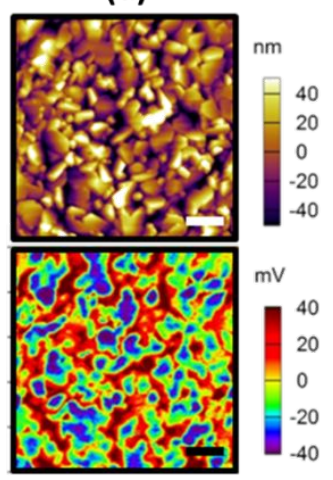

Figure 1 - Topography (top panel) and surface potential (bottom panel) measurements of $\mathrm{CH}_{3} \mathrm{NH}_{3} \mathrm{PbI}_{3}$ thin films on FTO glass formed from (a) DMF, (b) DMF (anti-solvent quench, DMF-SQ), (c) ACN/MA and (d) ACN/MA $\left(\mathrm{CH}_{3} \mathrm{NH}_{3} \mathrm{Cl}\right.$ post-treatment $\left.\mathrm{ACN} / \mathrm{CH}_{3} \mathrm{NH}_{3} \mathrm{Cl}\right)$, scale bars are $1 \mu \mathrm{m}$ in all cases. 
It has been well established that the morphology of perovskite thin films can be strongly influenced by the substrate upon which it is deposited. In the literature there have been many reported $\mathrm{n}$ - and p-type interlayers, which have been implemented in $\mathrm{CH}_{3} \mathrm{NH}_{3} \mathrm{PbI}_{3}$ based devices, however the use of FTO glass as an electrode has been almost ubiquitous. As such to try to provide a more widely applicable comparison of the perovskite morphologies studied herein FTO glass has been used as the substrate in this work.

There are clear differences in morphology between films prepared from DMF and those from ACN. $\mathrm{CH}_{3} \mathrm{NH}_{3} \mathrm{PbI}_{3}$ films formed from DMF (one-step processing) are discontinuous and have a high RMS roughness $\left(\mathrm{R}_{\mathrm{q}}\right.$ ) (see Table $\mathrm{S} 1$ for all $\mathrm{R}_{\mathrm{q}}$ values) (Figure 1a). Films formed from DMF (anti-solvent quench) are continuous and exhibit a smaller grain size (Figure 1b). As such typical roughness values are significantly lower using a solvent quenching step. ACN/MA films both with and without the post-treatment step show significantly more defined grains in the observed features. The addition of the $\mathrm{CH}_{3} \mathrm{NH}_{3} \mathrm{Cl}$ post-treatment promotes larger grains and an increase in surface roughness. Whilst these images show the morphology of films prepared on FTO glass, the morphologies closely match that reported previously of identical films prepared on FTO glass with a $\mathrm{TiO}_{2}$ hole transporting layer. ${ }^{3}$

Accompanying these changes in morphology is the emergence of large variations in surface potential across the films, as measured by SKPM. The changes in surface potential follow topographical features, explicitly different grains exhibit different surface potentials, correlated to differences in the local work function. Films comprised of smaller grains (DMF-SQ) show the smallest variance in surface potential in the areas probed (a range of $20 \mathrm{mV}$ ), while larger grained films exhibit a wider range of surface potentials (variances of approximately $40 \mathrm{mV}$ and $80 \mathrm{mV}$ for the $\mathrm{ACN} / \mathrm{MA}$ and $\mathrm{ACN} / \mathrm{CH}_{3} \mathrm{NH}_{3} \mathrm{Cl}$ films respectively). Whilst absolute values for 
work function cannot be measured using SKPM, these measurements highlight considerable local work function variation across the film surfaces. Films from ACN exhibit larger variations in local work function than those from DMF, but exhibit larger "domains" of a single local work function.

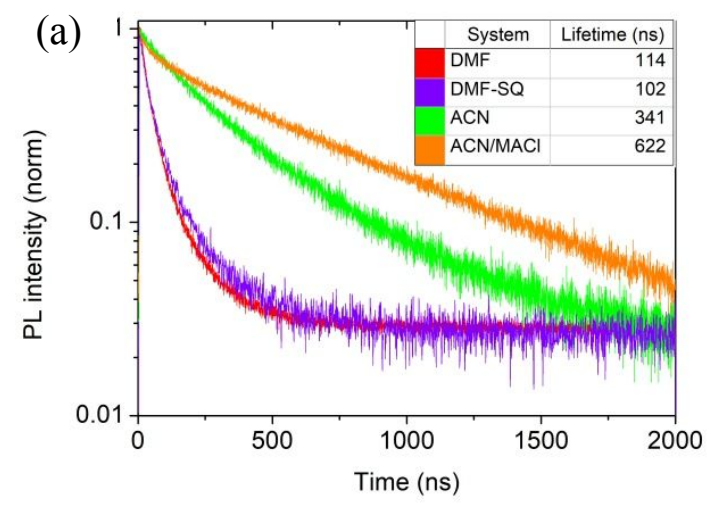

(b)

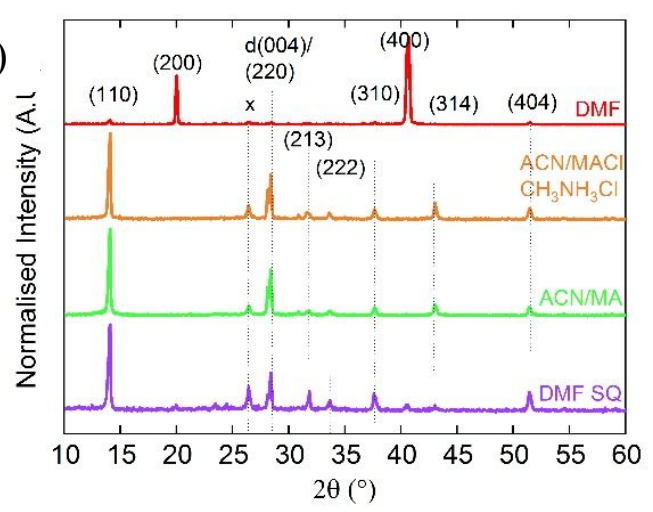

Figure 2 - (a) Time-resolved photoluminescence decays and (b) X-ray diffractograms of $\mathrm{CH}_{3} \mathrm{NH}_{3} \mathrm{PbI}_{3}$ thin films on FTO glass formed from DMF, DMF with an anti-solvent quench (DMF-SQ), ACN/MA and ACN/MA with a $\mathrm{CH}_{3} \mathrm{NH}_{3} \mathrm{Cl}\left(\mathrm{ACN} / \mathrm{CH}_{3} \mathrm{NH}_{3} \mathrm{Cl}\right.$ ) post-treatment. Films used in PL measurements were prepared on glass without an FTO coating.

To examine the lifetimes of charge carriers within these films, time-resolved photoluminescence (TRPL) decay measurements were carried out (see Figure 2a). The films used in these 
measurements were prepared onto glass without an FTO coating. The longer the photoluminescence lifetime, the slower the non-radiative decay is assumed to be and therefore it is assumed that charge carriers have longer PL lifetimes. A number of factors influence the photoluminescence decay including, but not limited to, the optoelectronic homogeneity of the films and their radiative and non-radiative decay constants, with the latter governed by defect densities. The data were fit with a stretched exponential function to allow quantification of the photoluminescence lifetime, this model has been suggested to account for a distribution of monomolecular recombination rates. ${ }^{18,19}$ Whilst this model does not account for bimolecular recombination it allows direct comparison of each of the extracted PL lifetimes reported here. The $\mathrm{ACN} / \mathrm{CH}_{3} \mathrm{NH}_{3} \mathrm{Cl}$ and $\mathrm{ACN} / \mathrm{MA}$ films both exhibit considerably longer average lifetimes $\langle\tau\rangle$ (662 ns and $341 \mathrm{~ns}$, respectively) than DMF-SQ and DMF (100 ns and $114 \mathrm{~ns}$ respectively). This agrees qualitatively with previous work and suggests that films formed from ACN/MA exhibit significantly improved optoelectronic properties than their DMF counterparts. ${ }^{3}$

X-ray diffraction measurements from all films exhibit peaks which can be attributed to the tetragonal $\mathrm{CH}_{3} \mathrm{NH}_{3} \mathrm{PbI}_{3}$ crystal structure (Figure $2 \mathrm{~b}$ ). ${ }^{20}$ Although the films produced from DMF show additional peaks when compared with those made from ACN/MA, all peaks can be indexed using the same crystal structure. Each of the $\mathrm{CH}_{3} \mathrm{NH}_{3} \mathrm{PbI}_{3}$ thin films in question are therefore isostructural, the differences are due to crystallographic texture changes. The additional peaks in the DMF formed films are most likely due to a lower degree of preferred orientation than those formed from ACN/MA. Changes in electronic or physical properties of the films, all composed of the same kind of crystallite, are clearly a direct result of the processing conditions especially the solvent systems used in their formation. 
To examine the chemistry of the uppermost surface of the perovskite layer (1-2 atomic layers) low energy ion scattering (LEIS) measurements were employed (Figure 3).
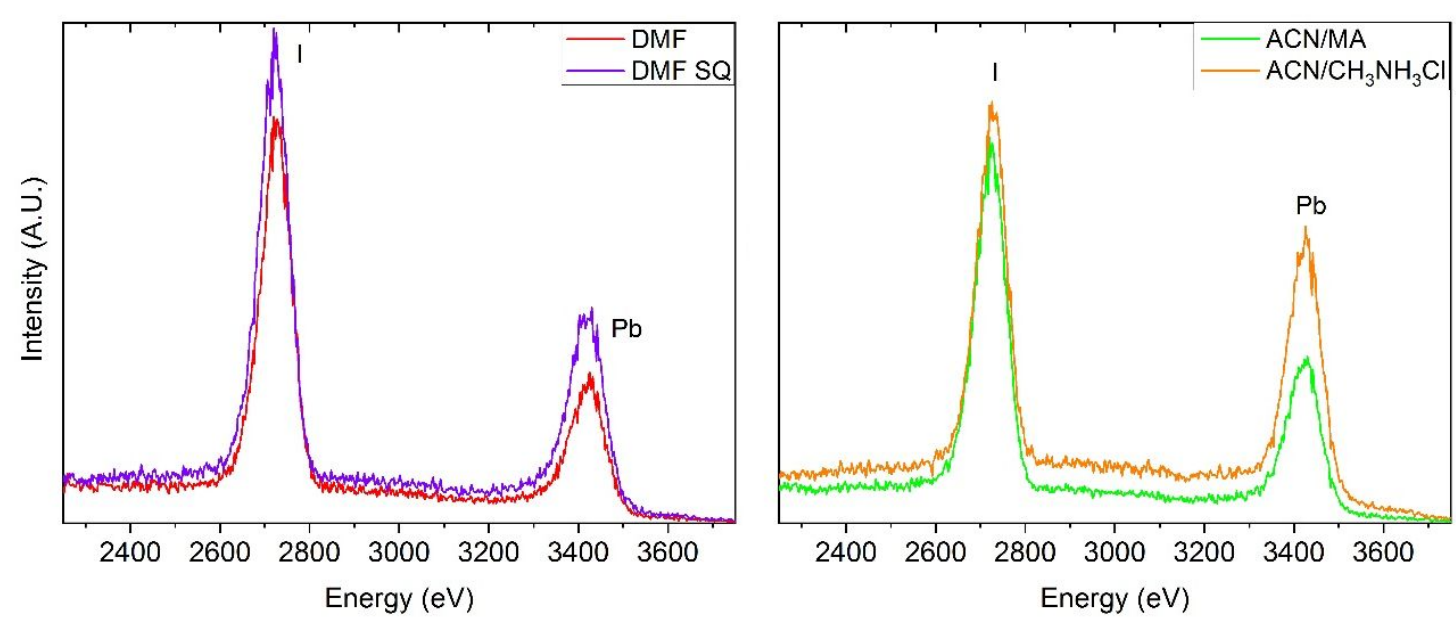

Figure 3 - Low energy ion scattering measurements of $\mathrm{CH}_{3} \mathrm{NH}_{3} \mathrm{PbI}_{3}$ films using a $\mathrm{Ne}^{+}$source. Left panel shows ion scattering of films formed from DMF, right panel shows ion scattering of films formed from ACN.

Ion scattering was carried out using both $\mathrm{Ne}^{+}$and $\mathrm{He}^{+}$sources, as scattering using $\mathrm{He}^{+}$provides a broader range of elemental detection while $\mathrm{Ne}^{+}$allows higher resolution measurements of $\mathrm{Pb}$ and I. LEIS spectra acquired using $\mathrm{He}^{+}$are shown in the supporting information, Figure $\mathrm{S} 1$. The differences in peak intensity observed in Figure 3 are indicative of genuine differences in surface chemistry of perovskite films. Whilst peaks were observed, in all systems, for $\mathrm{Pb}$ and I atoms no peaks corresponding to $\mathrm{N}$ or $\mathrm{C}$ atoms were observed. This implies a total absence of the organic component of the perovskite structure in the topmost atomic layers of these films. Additionally no $\mathrm{Cl}$ is observed in the surfaces of films which have undergone MACl post-treatment. The absence of the organic component in these measurements may suggest that the perovskite grains are all $\mathrm{Pb}$ or I terminated as only the topmost 1-2 layers are undergoing scrutiny. Alternatively 
the absence of the organic component in the very top of the film may be a result of loss of $\mathrm{CH}_{3} \mathrm{NH}_{3}{ }^{+}$on introduction of these samples to high vacuum as the high vapor pressure of methylammonium is well documented. ${ }^{21}$ We believe that the latter scenario is most likely responsible for the lack of carbon detected in this measurement. In the fabrication of perovskite PV devices electrodes are routinely deposited through metal evaporation in a high vacuum environment. If the lack of signal corresponding to the organic component of the films is due to the measurement occurring in high vacuum this process is representative of that experienced by the perovskite film in the majority of PV devices.

Although LEIS measurements are highly surface and atom identity sensitive and they do not provide any information relating to chemical bonding or environment. This was investigated using x-ray photoelectron spectroscopy (XPS) experiments on films produced in an identical manner. High resolution XPS spectra corresponding to the $\mathrm{Pb} 4 f, \mathrm{I} 3 d$ and $\mathrm{N} 1 s$ orbitals are shown in the supporting information Figures S3 and S4, for DMF and ACN systems respectively, those relating to $\mathrm{C} 1 s$ can be found in Figure S5.

Core level peaks were observed for I $3 d$ at binding energy values of $619.6 \mathrm{eV}$ for all films and are attributed to $\mathrm{PbI}_{2} \cdot{ }^{22}$ There is an additional feature at $\sim 618 \mathrm{eV}$ however the $\mathrm{I} 3 d$ line shape is consistent across the samples indicating this is due to the line shape rather than an additional bonding environment or distinct chemical species. Peaks for N $1 s$ were observed at $402.7 \mathrm{eV}$ for all samples, an additional peak was observed in those samples formed from ACN/MA at 401.2 $\mathrm{eV}$. These peaks have been previously attributed to the ${ }^{+} \mathrm{NH}_{3}-\mathrm{CH}_{3}$ and $\mathrm{NH}_{2} \mathrm{CH}_{3}$, respectively, in the literature and this assignment is used here. ${ }^{23-25}$ The presence of the lower binding energy peak in the samples formed from ACN/MA is due to either the presence of free methylammonium or residual ACN within the films, resulting from its addition to the solvent 
system. $\mathrm{Pb} 4 f$ peaks are present at $138.8 \mathrm{eV}$ and $137.3 \mathrm{eV}$ in all samples, however significantly more is present in those formed from the ACN based systems, these peaks can be attributed to $\mathrm{PbI}_{2}$ and $\mathrm{Pb}^{0}$, respectively. ${ }^{11,26}$ Methylamine is a well-documented reducing agent and leads to some reduction of $\mathrm{Pb}^{2+}$ to $\mathrm{Pb}^{0}$, increasing the proportion of $\mathrm{Pb}^{0}$ present in solutions to which it is added. ${ }^{27}$ The differences in chemical composition between films are most apparent in the $\mathrm{N} 1 \mathrm{~s}$ spectra. An additional N 1 s peak, attributed to methylamine, is observed in ACN samples but does not alter the crystal structure as measured by XRD. C $1 s$ spectra confirm the presence of both ${ }^{+} \mathrm{NH}_{3} \mathrm{CH}_{3}$ and $\mathrm{C}-\mathrm{H}$ containing species ( $285 \mathrm{eV}$ and $\left.286 \mathrm{eV}\right)$, attributed to the methylamine group of $\mathrm{CH}_{3} \mathrm{NH}_{3} \mathrm{PbI}_{3}$. Small amounts of additional carbon containing species (such as $\mathrm{C}-\mathrm{OH}$ and $\mathrm{C}=\mathrm{O}$ ) are also present in varying amounts in each sample. These are most likely due to residual solvent and the slight differences observed in the amounts of each species present is therefore unsurprising. The absence of $\mathrm{Cl}$ in the $\mathrm{ACN} / \mathrm{CH}_{3} \mathrm{NH}_{3} \mathrm{Cl}$ samples ion scattering data matches the lack of $\mathrm{Cl}$ in XPS data (see Figure S7). A table of peak positions for all samples and their corresponding bonding environments can be found in the supporting information.

LEIS and XPS data were used to approximate the chemical stoichiometry of the studied surfaces of the perovskites films, with LEIS measurements probing the top 1-2 atomic layers and XPS probing $\sim 10 \mathrm{~nm}$ into the film (shown in Tables 1 and 2). 


\begin{tabular}{|l|r|r|}
\hline Solvent system & Iodine & \multicolumn{1}{l|}{ Lead } \\
\hline DMF & 1.9 & 1 \\
\hline DMF-SQ & 2.4 & 1 \\
\hline ACN & 1.5 & 1 \\
\hline ACN $/ \mathrm{CH}_{3} \mathrm{NH}_{3} \mathrm{Cl}$ & 1.4 & 1 \\
\hline
\end{tabular}

Table 1 - Approximate stoichiometry of utmost surface of $\mathrm{CH}_{3} \mathrm{NH}_{3} \mathrm{PbI}_{3}$ films as determined by low energy ion scattering (LEIS) measurements (area of surface probed by scattering is $1 \mathrm{~mm}^{2}$, this technique probes the first few atomic layers).

\begin{tabular}{|l|r|r|r|r|r|r|l|}
\hline Solvent system & Lead & Iodine & Carbon & Nitrogen & Tin & Oxygen & $\begin{array}{l}\text { Lead to iodine } \\
\text { ratio (I : Pb) }\end{array}$ \\
\hline DMF & 1.7 & 6.2 & 3.7 & 1.6 & 1 & 2.2 & $3.6: 1$ \\
\hline DMF-SQ & 1.0 & 3.8 & 2.0 & 1 & 0 & 0 & $3.8: 1$ \\
\hline ACN & 1.4 & 4.3 & 20 & 1 & 0 & 0 & $3.1: 1$ \\
\hline $\mathrm{ACN} / \mathrm{CH}_{3} \mathrm{NH}_{3} \mathrm{Cl}$ & 4.1 & 9.4 & 3.4 & 1 & 0 & 0 & $2.4: 1$ \\
\hline
\end{tabular}

Table 2 - Approximate composition of the surface of $\mathrm{CH}_{3} \mathrm{NH}_{3} \mathrm{PbI}_{3}$ films as determined by x-ray photoelectron spectroscopy measurements (area of surface probed by scattering is $300 \mathrm{x} 700$ $\mu \mathrm{m}^{2}$, this measurement probes the first $10 \mathrm{~nm}$ of the surface). 
The I: $\mathrm{Pb}$ ratios observed at the topmost surfaces (as determined from LEIS) all deviate from the ideal ratio of 3:1 (I: $\mathrm{Pb})$ expected the average chemical stoichiometry averaged across a single crystal devoid from defects. However when greater depths of the sample are probed, through XPS measurements, the $\mathrm{I}: \mathrm{Pb}$ ratios are much closer to this $3: 1$ ratio. These observations suggest a structure in which the first few atomic layers are $\mathrm{PbI}_{2}$ terminated with evolution toward the bulk crystal structure of $\mathrm{CH}_{3} \mathrm{NH}_{3} \mathrm{PbI}_{3}$ deeper in to the sample. In fact recent work has demonstrated the impact of surface chemistry variations on the electronic and charge transport properties of $\mathrm{CH}_{3} \mathrm{NH}_{3} \mathrm{PbI}_{3}{ }^{28}$ In addition the chemical termination of $\mathrm{CH}_{3} \mathrm{NH}_{3} \mathrm{PbI}_{3}$ films defines their valence and conduction band energies; surfaces which are $\mathrm{Pb}$-I terminated exhibit energies up to $1 \mathrm{eV}$ lower than their MAI terminated counterparts. ${ }^{29}$

Depth-profiling time-of-flight secondary ion mass spectrometry (ToF-SIMS) measurements were carried out to monitor changes in film chemistry through the entirety of their thickness. During depth-profiling sputtering experiments (through the entirety of each of the films) positive and negative secondary ions were detected, separately, and are reported in Figure 6 as a function of sputtering time.

Ions relating to components of the $\mathrm{CH}_{3} \mathrm{NH}_{3} \mathrm{PbI}_{3}$ films $\left({ }^{206} \mathrm{~Pb}^{+}, \mathrm{Pb}^{+}, \mathrm{I}^{-}, \mathrm{NH}_{4}{ }^{+}, \mathrm{Cl}^{-}\right)$and $\mathrm{FTO}\left(\mathrm{O}^{-}\right)$ were each measured. The depth profiles shown in the supplementary information Figure S8 can be used to approximate the position of the interface between the $\mathrm{CH}_{3} \mathrm{NH}_{3} \mathrm{PbI}_{3}$ and the FTO as the observation of FTO $\left(\mathrm{O}^{-}\right.$ions $)$related species plateaus when sputtering reaches deep in to the FTO film. As such the bottommost part of the perovskite films is just before the plateau of the traces. At this point the traces corresponding to positive ions $\left({ }^{206} \mathrm{~Pb}^{+}, \mathrm{Pb}^{+}\right.$and $\left.\mathrm{NH}_{4}^{+}\right)$, for all films, show a sudden decrease in detection followed by plateaus, decaying in a roughly exponential form. In films formed from ACN/MA this initial slope is steeper than for the DMF- 
cast films suggesting positive ion production by sputtering is easier in DMF rather than ACN films. Films fabricated from DMF and DMF-SQ show significantly different shapes of the depth profiles for both $\mathrm{I}^{-}$and $\mathrm{O}^{-}$. This is a result of pin-holes and large thickness variations in the perovskite films with bare FTO exposed within the region being sputtered, this leads to $\mathrm{O}^{-}$ observation much earlier in the depth profiling process than in ACN films. As a result the slopes of $\mathrm{I}^{-}$and $\mathrm{O}^{-}$traces are less steep with no sharp interface between the $\mathrm{CH}_{3} \mathrm{NH}_{3} \mathrm{PbI}_{3}$ film and the FTO substrate (ions are concomitantly generated during the depth profile). Conversely the same species in DMF-SQ exhibit sharper slopes on both the rising $(\mathrm{O})$ and falling $(\mathrm{I})$ edges suggesting a sharper interface and uniform ion distribution, similar to the films formed from ACN/MA and $\mathrm{ACN} / \mathrm{CH}_{3} \mathrm{NH}_{3} \mathrm{Cl}$. The sputtering profile of $\mathrm{I}^{-}$ions throughout the $\mathrm{ACN}$ films is flat-topped suggestive of more even distribution of ions throughout both DMF and DMF-SQ. Despite the relatively even ion distribution in the bulk of the film, an accumulation of $\mathrm{I}^{-}$is inferred from the additional rise in signal at the interface with the $\mathrm{FTO}$ substrate. The $\mathrm{CH}_{3} \mathrm{NH}_{3} \mathrm{Cl}$ post treatment results in a bimodal distribution of $\mathrm{Cl}^{-}$inside the $\mathrm{CH}_{3} \mathrm{NH}_{3} \mathrm{PbI}_{3}$ with no observable difference to the out-of-plane crystal structure in XRD patterns. The traces for $\mathrm{I}^{-}$and $\mathrm{Cl}^{-}$both drop at the same sputtering time (around 100 seconds) suggesting segregation of the both halide ions. Similarly to the methylamine detected by XPS, this segregation isn't manifested in differences to structural properties of these films. SIMS is acutely sensitive to changes in chemical composition, and is considerably more sensitive than XPS to compositional changes. As such change to the composition of films, responsible for the unusual $\mathrm{Cl}^{-}$and $\mathrm{I}^{-}$traces observed in $\mathrm{ACN} / \mathrm{CH}_{3} \mathrm{NH}_{3} \mathrm{Cl}$ samples, may be present below the detection threshold of the other techniques employed in this work. The distribution of chemical species is unique to each solvent system, however films formed from $\mathrm{ACN}$ are most self-consistent and exhibit the most uniform distribution of ions. 
Greater uniformity is consistent with these films being less defective and more homogenous, which should result in few defects responsible for electronic trapping and trap assisted recombination. This manifests as higher charge carrier lifetimes, and ultimately more efficient photovoltaic device performance.

Ultraviolet photoelectron spectroscopy (UPS) measurements were obtained from the same samples as XPS spectra to elucidate the valence electronic structure of $\mathrm{CH}_{3} \mathrm{NH}_{3} \mathrm{PbI}_{3}$ films. The valence band and secondary electron cut-off regions of the UPS spectra (supplementary information Figure S9) were used to determine the positions of the valence band maxima and work functions of each film. The extracted work function (WF) and valence band maximum (VBM) values from these UPS spectra are presented in Table 3.

\begin{tabular}{|c|r|r|}
\hline & $\begin{array}{r}\text { Work function } \\
(\mathrm{eV})\end{array}$ & \multicolumn{1}{|c|}{ Valence band } \\
& 4.4 & 5.7 \\
\hline $\mathrm{DMF}$ & 4.5 & 5.7 \\
\hline $\mathrm{DMF}-\mathrm{SQ}$ & 4.7 & 5.8 \\
\hline $\mathrm{ACN} / \mathrm{MA}$ & 5.3 & 6.3 \\
\hline $\mathrm{ACN} / \mathrm{CH}_{3} \mathrm{NH}_{3} \mathrm{Cl}$ & & \\
\hline
\end{tabular}

Table 3 - Work function and valence band maximum energies determined from UPS measurements.

With the exception of the $\mathrm{ACN} / \mathrm{CH}_{3} \mathrm{NH}_{3} \mathrm{Cl}$ films all measured films exhibit VBM energies between 5.7 and 5.8eV. Although the VBM energy is very similar for all films, there are significant differences in the character of the VB spectra of each system. This would suggest that 
changes in the relative contribution of the frontier orbitals of $\mathrm{CH}_{3} \mathrm{NH}_{3} \mathrm{PbI}_{3}$ to the valence band are being observed. As all films are isostructural, these changes in electronic structure must be a direct result of subtle differences induced in chemistry, and are therefore due to the solvent system employed in each films fabrication.

The $\mathrm{ACN} / \mathrm{CH}_{3} \mathrm{NH}_{3} \mathrm{Cl}$ film exhibits the most significantly different VBM $(6.3 \mathrm{eV})$ and the largest work function $(5.3 \mathrm{eV})$. A significant range of VBM and WF energies have been reported for $\mathrm{CH}_{3} \mathrm{NH}_{3} \mathrm{PbI}_{3}$ films and these data are in agreement with many previous studies. ${ }^{30-32}$ The $\mathrm{CH}_{3} \mathrm{NH}_{3} \mathrm{Cl}$ post treatment significantly affects both the WF and VBM of the $\mathrm{CH}_{3} \mathrm{NH}_{3} \mathrm{PbI}_{3}$ films.

Although these values are within the reported ranges for both WF and $\mathrm{VBM}$ of $\mathrm{CH}_{3} \mathrm{NH}_{3} \mathrm{PbI}_{3}$ films it is apparent that there is a significant increase in the energy levels of $\mathrm{ACN} / \mathrm{CH}_{3} \mathrm{NH}_{3} \mathrm{Cl}$ film with the MACl post-treatment. UPS is a surface sensitive technique so it may be that the changes to the electronic structure measured here of the $\mathrm{MACl}$ treated films occurs only at the surface of the thin films. However, it is clear from the XPS, the TRPL and SPM measurements discussed previously that these post-treated films exhibit significant changes in both their electronic and morphological structure. In particular the TRPL and SKPM measurements show clear changes in the bulk structure of the films, compared to the others, which would be reflected in changes to the electronic structure.

To corroborate the effects of the resulting changes in chemistry and energy levels with photovoltaic device performance devices with the following architecture $\left(\mathrm{FTO} / \mathrm{SnO}_{2} /\right.$ $\mathrm{CH}_{3} \mathrm{NH}_{3} \mathrm{PbI}_{3} /$ spiro-OMeTAD/Ag) were fabricated and the current-density voltage (JV) characteristics of the best performing devices are shown in Figure 4. 

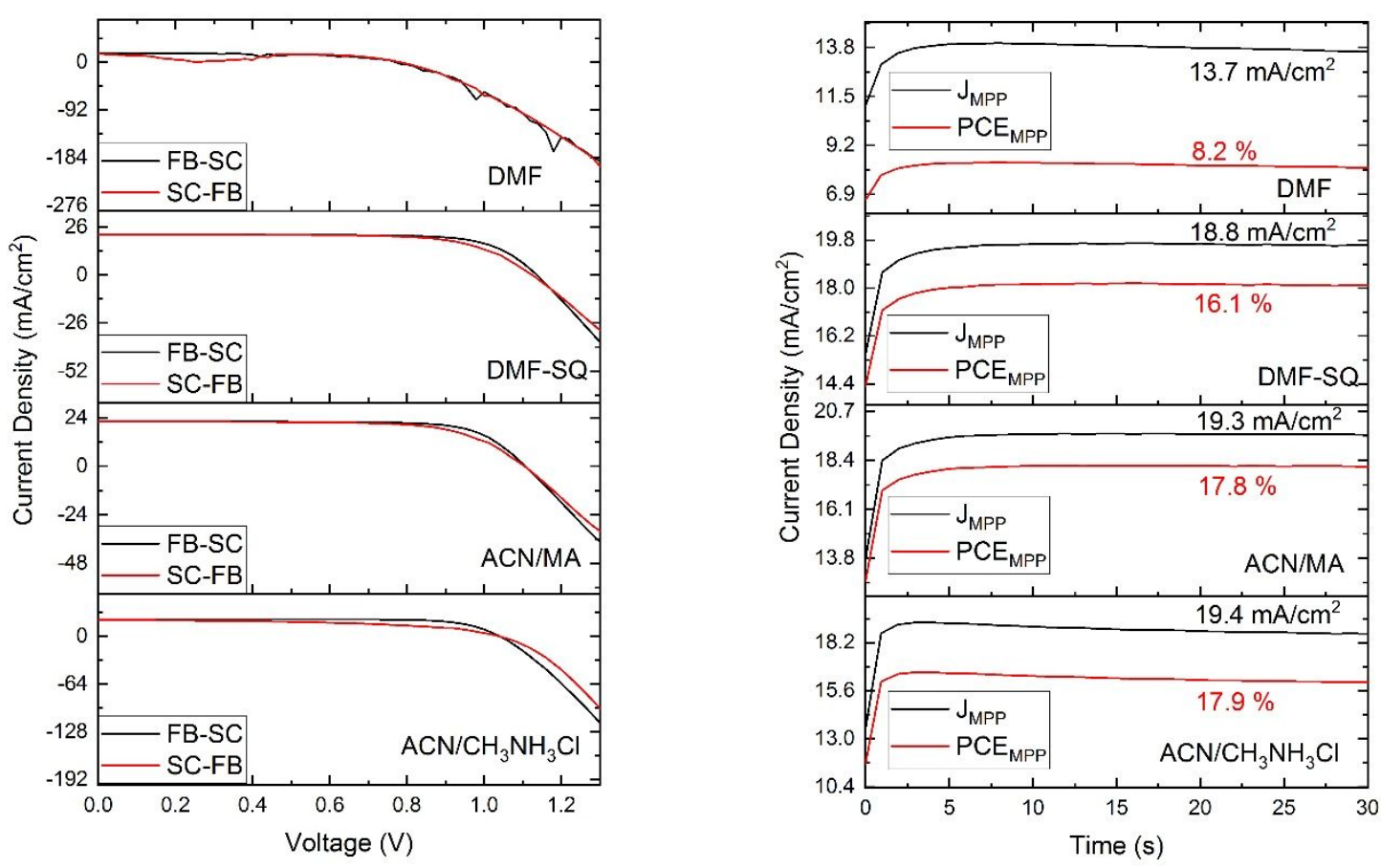

Figure 4 - Current voltage characteristics. Current-voltage characteristics of the champion DMF, DMF-SQ, ACN/MA and $\mathrm{ACN} / \mathrm{CH}_{3} \mathrm{NH}_{3} \mathrm{Cl}$ devices and their respective stabilised photocurrents and efficiencies. Performance parameters for each of these devices are given in Table 4.

\begin{tabular}{|c|c|c|c|c|c|}
\hline $\begin{array}{c}\text { Perovskite } \\
\text { Solvent }\end{array}$ & & $\mathrm{J}_{\mathrm{SC}}\left(\mathrm{mA} \mathrm{cm} \mathrm{cm}^{-2}\right)$ & $\mathrm{V}_{\mathrm{OC}}(\mathrm{V})$ & F.F. & $\eta(\%)$ \\
\hline \multirow[t]{2}{*}{$\mathrm{DMF}$} & Average & 17.14 & 0.79 & 0.55 & 7.42 \\
\hline & Champion & 17.6 & 0.78 & 0.59 & 8.01 \\
\hline \multirow[t]{2}{*}{ DMF-SQ } & Average & 22.5 & 1.04 & 0.75 & 17.3 \\
\hline & Champion & 22.5 & 1.06 & 0.77 & 17.9 \\
\hline \multirow[t]{2}{*}{$\mathrm{ACN}$} & Average & 21.9 & 1.10 & 0.71 & 17.2 \\
\hline & Champion & 22.2 & 1.13 & 0.74 & 18.5 \\
\hline
\end{tabular}




\begin{tabular}{|l|l|r|r|r|r|}
\hline ACN/MACl & Average & 21.9 & 1.11 & 0.73 & 17.8 \\
\hline & Champion & 21.8 & 1.13 & 0.75 & 18.7 \\
\hline
\end{tabular}

Table 4 - Average and champion device performance parameters.

Complete performance parameters for this batch of devices can be found in the supplementary information (Figure S10). For photovoltaic devices fabricated using DMF without a solvent quench, the poorest performance parameters were obtained. This is easily explained by the discontinuity of the perovskite layer causing a decrease in the amount of light which can be absorbed, and increasing the available shunting pathways in the device. The addition of a solvent quenching step during spin coating, produces a marked increase in all performance parameters, directly correlated to an improvement in surface coverage. The improvement in overall performance using the ACN/MA solvent is as a result of an increase in the open-circuit voltages obtained. This is likely due to the shift in surface potential of these perovskite films. The $\mathrm{CH}_{3} \mathrm{NH}_{3} \mathrm{Cl}$ post treatment results in a small improvement in device efficiency $(18.7 \%$ for the champion) compared to the $\mathrm{ACN}$ route without post-treatment (18.5\% for the champion). The improved parameters of both ACN based routes (compared to DMF-SQ devices) are demonstrative of the improvements in morphology, local work function distribution, electronic properties and therefore charge carrier lifetimes observed using this solvent system. The changes in electronic and chemical properties reported here are not related to modification of crystal structure. These changes can be attributed to differences in chemistry of perovskite films caused by the ACN/MA solvent system for processing $\mathrm{CH}_{3} \mathrm{NH}_{3} \mathrm{PbI}_{3}$ films. The differences induced by combining methylamine with the $\mathrm{ACN}$ solvent produce $\mathrm{CH}_{3} \mathrm{NH}_{3} \mathrm{PbI}_{3}$ with more desirable properties for photovoltaic devices, resulting in superior device performance. 


\section{CONCLUSIONS}

Methylammonium lead iodide thin films processed using an ACN/MA composite solvent system were shown to have significantly different physical and electronic properties than their DMF processed counterparts. Films formed from ACN/MA are isostructural with those formed from DMF, but demonstrate longer charge carrier lifetimes, more desirable morphologies and smaller variations in both local work function and chemical composition. These differences are a direct result of the choice of solvent system and have been directly measured, for the first time here. Thorough understanding of the chemistry of perovskite precursor solutions from data of this kind will provide means to optimise and induce desirable electronic and chemical properties in perovskite materials, assisting their introduction to the commercial market.

\section{Supporting Information.}

Experimental methods, additional AFM images and LEIS scattering, C1s XPS and device statistics.

\section{AUTHOR INFORMATION}

Corresponding Author

*Email: Alexandra.ramadan@physics.ox.ac.uk and henry.snaith@physics.ox.ac.uk

\section{Notes}


The authors declare no competing financial interests.

\section{ACKNOWLEDGMENT}

The authors thank O. J. Ashton for the TOC figure. AJR and HJS acknowledge the

Engineering and Physical Sciences Research Council for funding grant numbers

EP/M005143/1 and EP/M015254/1. NKK acknowledges the Princeton Center for

Complex Materials for funding. The XPS/UPS system used in this research was funded

through the Science City Research Alliance (SCRA) Advanced Materials Project 1:

"Creating and Characterizing Next Generation of Advanced Materials" with support from

Advantage West Midlands (AWM) and the European Regional Development Fund

(ERDF).

References

(1) McMeekin, D. P.; Sadoughi, G.; Rehman, W.; Eperon, G. E.; Saliba, M.; Horantner, M. T.; Haghighirad, A.; Sakai, N.; Korte, L.; Rech, B.; et al. A Mixed-Cation Lead MixedHalide Perovskite Absorber for Tandem Solar Cells. Science (80-. ). 2016, 351 (6269), $151-155$.

(2) NREL. Best Research Cell Efficiencies http://www.nrel.gov/pv/assets/images/efficiency_chart.jpg. 
(3) Noel, N. K.; Habisreutinger, S. N.; Wenger, B.; Klug, M. T.; Hörantner, M. T.; Johnston, M. B.; Nicholas, R. J.; Moore, D. T.; Snaith, H. J. A Low Viscosity, Low Boiling Point, Clean Solvent System for the Rapid Crystallisation of Highly Specular Perovskite Films. Energy Environ. Sci. 2017, 10 (1), 145-152.

(4) McConvey, I. F.; Woods, D.; Lewis, M.; Gan, Q.; Nancarrow, P. The Importance of Acetonitrile in the Pharmaceutical Industry and Opportunities for Its Recovery from Waste. Org. Process Res. Dev. 2012, 16 (4), 612-624.

(5) Zhou, Z.; Wang, Z.; Zhou, Y.; Pang, S.; Wang, D.; Xu, H.; Liu, Z.; Padture, N. P.; Cui, G. Methylamine-Gas-Induced Defect-Healing Behavior of CH 3 NH 3 PbI 3 Thin Films for Perovskite Solar Cells. Angew. Chemie Int. Ed. 2015, 54 (33), 9705-9709.

(6) Conings, B.; Bretschneider, S. A.; Babayigit, A.; Gauquelin, N.; Cardinaletti, I.; Manca, J.; Verbeeck, J.; Snaith, H. J.; Boyen, H.-G. Structure-Property Relations of Methylamine Vapor Treated Hybrid Perovskite CH 3 NH 3 PbI 3 Films and Solar Cells. ACS Appl. Mater. Interfaces 2017, 9 (9), 8092-8099.

(7) Manser, J. S.; Saidaminov, M. I.; Christians, J. A.; Bakr, O. M.; Kamat, P. V. Making and Breaking of Lead Halide Perovskites. Acc. Chem. Res. 2016, 49 (2), 330-338.

(8) Nayak, P. K.; Moore, D. T.; Wenger, B.; Nayak, S.; Haghighirad, A. A.; Fineberg, A.;

Noel, N. K.; Reid, O. G.; Rumbles, G.; Kukura, P.; et al. Mechanism for Rapid Growth of Organic-inorganic Halide Perovskite Crystals. Nat. Commun. 2016, 7, 13303.

(9) Guo, Y.; Shoyama, K.; Sato, W.; Matsuo, Y.; Inoue, K.; Harano, K.; Liu, C.; Tanaka, H.; Nakamura, E. Chemical Pathways Connecting Lead(II) Iodide and Perovskite via 
Polymeric Plumbate(II) Fiber. J. Am. Chem. Soc. 2015, 137 (50), 15907-15914.

(10) Noel, N. K.; Congiu, M.; Ramadan, A. J.; Fearn, S.; McMeekin, D. P.; Patel, J. B.;

Johnston, M. B.; Wenger, B.; Snaith, H. J. Unveiling the Influence of $\mathrm{pH}$ on the

Crystallization of Hybrid Perovskites, Delivering Low Voltage Loss Photovoltaics. Joule

2017, $1(2), 328-343$.

(11) Ramadan, A. J.; Rochford, L. A.; Fearn, S.; Snaith, H. J. Processing Solvent-Dependent Electronic and Structural Properties of Cesium Lead Triiodide Thin Films. J. Phys. Chem. Lett. 2017, 4172-4176.

(12) Sharenko, A.; Toney, M. F. Relationships between Lead Halide Perovskite Thin-Film Fabrication, Morphology, and Performance in Solar Cells. J. Am. Chem. Soc. 2016, 138 (2), 463-470.

(13) Saliba, M.; Tan, K. W.; Sai, H.; Moore, D. T.; Scott, T.; Zhang, W.; Estroff, L. A.; Wiesner, U.; Snaith, H. J. Influence of Thermal Processing Protocol upon the Crystallization and Photovoltaic Performance of Organic-Inorganic Lead Trihalide Perovskites. J. Phys. Chem. C 2014, 118 (30), 17171-17177.

(14) Zhao, Y.; Zhu, K. CH 3 NH 3 Cl-Assisted One-Step Solution Growth of CH 3 NH 3 PbI 3 : Structure, Charge-Carrier Dynamics, and Photovoltaic Properties of Perovskite Solar Cells. J. Phys. Chem. C 2014, 118 (18), 9412-9418.

(15) Zhao, Y.; Zhu, K. Efficient Planar Perovskite Solar Cells Based on 1.8 eV Band Gap CH 3 NH 3 PbI 2 Br Nanosheets via Thermal Decomposition. J. Am. Chem. Soc. 2014, 136 (35), 12241-12244. 
(16) Eperon, G. E.; Burlakov, V. M.; Docampo, P.; Goriely, A.; Snaith, H. J. Morphological Control for High Performance, Solution-Processed Planar Heterojunction Perovskite Solar Cells. Adv. Funct. Mater. 2014, 24 (1), 151-157.

(17) Im, J.-H.; Kim, H.-S.; Park, N.-G. Morphology-Photovoltaic Property Correlation in Perovskite Solar Cells: One-Step versus Two-Step Deposition of CH 3 NH 3 PbI 3. APL Mater. 2014, 2 (8), 81510.

(18) Stranks, S. D.; Eperon, G. E.; Grancini, G.; Menelaou, C.; Alcocer, M. J. P.; Leijtens, T.; Herz, L. M.; Petrozza, A.; Snaith, H. J. Electron-Hole Diffusion Lengths Exceeding 1 Micrometer in an Organometal Trihalide Perovskite Absorber. Science (80-. ). 2013, 342 (6156), 341-344.

(19) de Quilettes, D. W.; Vorpahl, S. M.; Stranks, S. D.; Nagaoka, H.; Eperon, G. E.; Ziffer, M. E.; Snaith, H. J.; Ginger, D. S. Impact of Microstructure on Local Carrier Lifetime in Perovskite Solar Cells. Science (80-. ). 2015, 348 (6235), 683-686.

(20) Jaffe, A.; Lin, Y.; Beavers, C. M.; Voss, J.; Mao, W. L.; Karunadasa, H. I. High-Pressure Single-Crystal Structures of 3D Lead-Halide Hybrid Perovskites and Pressure Effects on Their Electronic and Optical Properties. ACS Cent. Sci. 2016, 2 (4), 201-209.

(21) Zhao, L.; Kerner, R. A.; Xiao, Z.; Lin, Y. L.; Lee, K. M.; Schwartz, J.; Rand, B. P. Redox Chemistry Dominates the Degradation and Decomposition of Metal Halide Perovskite Optoelectronic Devices. ACS Energy Lett. 2016, 1 (3), 595-602.

(22) Sadoughi, G.; Starr, D. E.; Handick, E.; Stranks, S. D.; Gorgoi, M.; Wilks, R. G.; Bär, M.; Snaith, H. J. Observation and Mediation of the Presence of Metallic Lead in Organic- 
Inorganic Perovskite Films. ACS Appl. Mater. Interfaces 2015, 7 (24), 13440-13444.

(23) Raga, S. R.; Ono, L. K.; Qi, Y. Rapid Perovskite Formation by CH3NH2 Gas-Induced Intercalation and Reaction of PbI2. J. Mater. Chem. A 2016, 4 (7), 2494-2500.

(24) Chen, J. J.; Winograd, N. The Adsorption and Decomposition of Methylamine on Pd(111). Surf. Sci. 1995, 326 (3), 285-300.

(25) Calloni, A.; Abate, A.; Bussetti, G.; Berti, G.; Yivlialin, R.; Ciccacci, F.; Du?, L. Stability of Organic Cations in Solution-Processed CH 3 NH 3 PbI 3 Perovskites: Formation of Modified Surface Layers. J. Phys. Chem. C 2015, 119 (37), 21329-21335.

(26) Wagner, C. D.; Riggs, W. M.; Davis, L. E.; Moulder, J. F.; Muilenberg, G. E. Handbook of X-Ray Photoelectron Spectroscopy; 1979.

(27) Faber, M. K.; Fussa-Rydel, O.; Skowyra, J. B.; McMills, L. E. H.; Dye, J. L.

Methylamine-Assisted Solubilization of Lithium and Sodium Metals in Various Amine and Ether Solvents. J. Am. Chem. Soc. 1989, 111 (15), 5957-5958.

(28) Yang, Y.; Yang, M.; Moore, D. T.; Yan, Y.; Miller, E. M.; Zhu, K.; Beard, M. C. Top and Bottom Surfaces Limit Carrier Lifetime in Lead Iodide Perovskite Films. Nat. Energy 2017, 2 (2), 16207.

(29) Quarti, C.; De Angelis, F.; Beljonne, D. Influence of Surface Termination on the Energy Level Alignment at the CH 3 NH 3 PbI 3 Perovskite/C60 Interface. Chem. Mater. 2017, $29(3), 958-968$.

(30) Zu, F.-S.; Amsalem, P.; Salzmann, I.; Wang, R.-B.; Ralaiarisoa, M.; Kowarik, S.; Duhm, S.; Koch, N. Impact of White Light Illumination on the Electronic and Chemical 
Structures of Mixed Halide and Single Crystal Perovskites. Adv. Opt. Mater. 2017, 5 (9), 1700139.

(31) Schulz, P.; Edri, E.; Kirmayer, S.; Hodes, G.; Cahen, D.; Kahn, A. Interface Energetics in Organo-Metal Halide Perovskite-Based Photovoltaic Cells. Energy Environ. Sci. 2014, 7, $1377-1381$.

(32) Emara, J.; Schnier, T.; Pourdavoud, N.; Riedl, T.; Meerholz, K.; Olthof, S. Impact of Film Stoichiometry on the Ionization Energy and Electronic Structure of CH 3 NH 3 PbI 3 Perovskites. Adv. Mater. 2016, 28 (3), 553-559.

TOC IMAGE

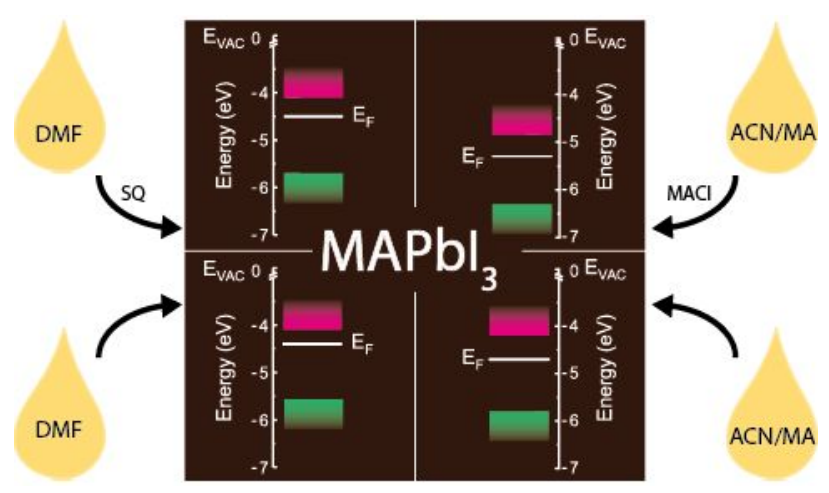

